Ragnar Lundström

Nora Räthzel

David Uzzell

\title{
Disconnected Spaces: introducing environmental perspectives into the trade union agenda top-down and bottom-up ${ }^{1}$
}

\begin{abstract}
Introduction ${ }^{2}$
The way we produce and what we produce determines the uses and misuses of nature. In recent years, some of the most enlightened climate change policies have been formulated by trade unions as they are highly conscious of the role and impact of production on the environment, and how climate change legislation may affect the livelihood of their members as well as their environment. If we accept this, then trade unions are indispensable actors if environmentally sustainable societies are to be created. Consequently, workers in every sector and in every country are central to the question of whether there is a future for human life on the planet.
\end{abstract}

The analysis presented in this paper was conducted as part of a larger research project about the role of individuals in transforming organisations. ${ }^{3}$ Our interest in the role of individuals for union transformation is a result of previous research into the climate policies of trade unions worldwide (Räthzel \& Uzzell 2013). Consistently, our informants stressed the importance of committed unionists with whom they cooperated or of individuals in environmental movements, pushing their organisation to cooperate with unions. Authors who have investigated coalition-building between environmental movements and unions, come to similar results, describing the importance of 'bridge-brokers', individuals with high degrees of legitimacy across the coalition (Mayer, 2009). Obach (2004) discusses the importance of individuals, who are able to broaden the mind-set of organisations, for instance because they are familiar with the cultures in both (213ff). While these authors concentrate on coalition

\footnotetext{
${ }^{1}$ To be published in Environmental Sociology

${ }^{2}$ The authors are extremely grateful to Sven Nyberg, Lars Henriksson, and Joaquín Nieto for their generous participation in the project and for comments on a previous version of the text. We owe our knowledge to their openness and insights. Any misinterpretations are entirely our responsibility. We also want to thank the two anonymous reviewers for their supportive and helpful comments.

${ }^{3}$ We are grateful to the Swedish Research Council (Vetenskapsrådet) for funding this project.
} 
building between organisations our focus is on the internal processes of change and the obstacles and possibilities, which individuals might find in changing the 'mind-set' of their organisation. The role of individuals in transforming organisations has primarily been discussed as an issue of leadership (Bass, 1999; Caldwell, 2003). The majority of these studies emphasises individual performance within an organisation, but without taking into account the broader societal contexts within which organisations act, and individuals develop their capabilities. The aim of our project is to understand individual and organisational trajectories in relationship to each other and to the societal contexts within which they develop. We have chosen a dual historical approach. Through life-history interviews we aim to understand the trajectories of individuals, who play a significant role in transforming their organisation. Through an analysis of the trajectory of the organisation we aim to understand the situation, within which it allows individuals to play such a role. Both trajectories are analysed within the societal background in which they unfold, thus combining the critical-psychological concept of 'societal capability to act' (Holzkamp, 2013) with the concept of 'affordances' drawn from developmental psychology (Gibson, 1979). We attempt to understand the overdetermination of biographical, organisational and political contexts within which individuals act to enable changes within organisations. The life-history method (like other qualitative methods) requires the researcher to be on the lookout for unexpected themes, as opposed to searching to prove their hypothesis. One of these unexpected themes we found by examining the Swedish material forms the content of this article: the life trajectories of two men, whose experiences led them to become environmentalists as well as unionists, who look back on a life of struggling to introduce climate change as a central issue into the union, believing they have not succeeded. Sad though this is, what really surprised us was that both men have been and are members of the same union, but they had never met. In a small country like Sweden, where the industrial unions are organised into one central organisation, the Swedish Trade Union Federation (LO) and where the number of environmentally committed unionists is not overwhelming this seemed worth scrutinising. We therefore selected these two life-histories to ask: how did Sven and Lars become committed to environmental and labour issues? What kind of strategies did they pursue to introduce the issue of climate change into the trade union agenda? How do they explain the failure of their efforts and how do they define failure? Why did they never meet? By answering these questions we 
want to shed light on the relationship between individual and organisational trajectories within specific societal (political and economic) conjunctures.

The article is organised as follows: the first section describes the method, the second summarises the trajectory of the Swedish unions. In the third section we analyse the life-histories of our two protagonists. We also introduce an element of our Spanish material, because it provides an alternative insight into what kind of environmental practices can be pursued by unionists in specific conjunctures. The last section draws some conclusions as to what can be learned from these specific cases in Sweden for the viability of climate change policies in trade unions in general.

\section{On method}

Life-history interviews are our main source of information because we are interested in the ways in which individuals understand their life trajectories. It is already the way in which life-stories are told that reveals something about the ways in which individuals see themselves within their societal and organisational contexts. As has been pointed out (Holstein \& Gubrium, 2003), interviews are a co-construction between the interviewer and the interviewee. However, that does not mean that lifestories are inventions, but rather that different aspects of a respondents life will be told differently in different contexts and at different times. The opportunites that lifehistories provide is to learn something about the ways in which people experience themselves as actors and how they act upon what they see as limitations, success or failure. The challenge for the researcher is to walk the thin line between taking stories at face value or giving them a meaning that corresponds more with the position of the researcher than with the experience of the respondents. One of our strategies to avoid the latter is to send our text to the interviewees. This process includes a negotiation between ours and the interpretations of the interviewee, whereby we reatain responsibility and the right to be wrong in the eyes of the respondents in the last instance. So far, we have never had to make decisive amendments to our analyses, even where respondents have been surprised by the ways in which we made sense of their stories. Surprises can also be new insights.

Technically, we conduct semi-structured interviews. Interviewees are asked to relate their life story beginning from the date of their birth, including the professions of their parents. We want the interviewees to decide about what they feel is important in their lives and worth talking about. However, they knew we were interested in trade union 
strategies regarding climate change and in individual trajectories into union work and into environmental issues. During the interview we ask questions pertaining to the stories we are told, asking for clarifications or for more details about issues the interviewees have brought up.

We have also read the official trade union documents on climate change policies and actions, the literature about the trade union histories in the specific countries, as well as acquiring information about the climate change politics of the respective countries. We have interviewed about 100 unionists, mostly union officials, who have been instrumental in formulating environmental programmes in their unions in Sweden, Spain, India, South Africa, Brazil, the UK and in international union federations.

By definition, individuals, who are trying to transform their organisation's frame of reference, its aims and thereby its self-conception, are not representative of the majority of their organisation. Would they represent the general consensus, there would be no need to change it. We wanted to find 'organic intellectuals' in Gramsci's sense: individuals who are able to articulate the experiences of a particular class or group in a way that enables them to become the creators of a new society. Organic intellectuals must be 'permanent persuaders', not just 'orators' wrote Gramsci (1999). In our case we were looking for individuals, who were changing not society at large, but 'only' the organisations within which they were working. We use the term 'organic intellectuals' as a heuristic tool. The term helps us to look out for something more than is implicit in the more generally used concept of 'change agents' (Caldwell, 2003), namely for individuals, who move 'from technique-as-work ... to technique-asscience and to the humanistic conception of history, without which one remains "specialised" and does not become "directive" (specialised and political)' (Gramsci 1999:142). Overcoming specialisation is what environmentally engaged individuals in trade unions need to do, in order to include climate change into their trade union agenda. The more trade unions develop into what Hyman called business unionism (Hyman, 2001) the more they specialise on the quantitative technical aspects of work (salaries, working hours) without accounting for the broader societal and socionatural context in which salaried labour is executed. While these responsibilities are central, caring for them exclusively implies not caring for them in the long run because the socio-natural conditions for work in general are ignored. Setting climate 
change on the trade union agenda is a step towards de-specialisation and becoming an organic intellectual. In difference to the concept of leaders, organic intellectuals can be found at any level of an organisation, from the top to the bottom. What defines them is the capability to articulate a new paradigm that broadens the capacity to act for social groups, who have a subordinate position in society at large. Whether the organic intellectual is successful or not is an important but secondary question. While we pursue the hypothesis that individuals are decisive for changing organisations, their ingenuity is only a necessary, not a sufficient condition for transformation. Since conditions keep changing and organic intellectuals differ across times and places there are no general rules for success. A case study is not a basis for generalisations but it may provide the possibility to learn something about people's possibilities to act, since it is closer to a 'multidimensional and unpredictable reality' (Flyvbjerg, 2006). What we hope to provide is some insight into the interconnectedness of individual capacities and limitations on the one side, organisational openings and barriers on the other, and how they interact with each other at specific conjunctures. These insights might be useful in other places, at other times, and under different conditions (Geertz, 1973).

\section{Trade Unions in Sweden}

It has been argued now for some time that organisations like trade unions are 'fading away' (Castells, 2000) due to the decline of the industrial sector, in which the collective mobilisation of workers has a strong tradition (Munck, 2002), processes of fragmentation and deregulation of labour market policies (Gray, 2004) leading to decreasing levels of union membership (Kjellberg, 2011). Against this background some have argued that unions could be revitalised through strategies that integrate precarious and informal workers (Frege \& Kelly, 2004) or through taking up new perspectives that interest predominantly younger people, like environmental issues (Räthzel \& Uzzell, 2012; Snell \& Fairbrother, 2010; Hampton, 2015). In Sweden union membership has decreased as well, although from a very high level. They have decreased by about $15 \%$ over the last three decades, averaging today at about $70 \%$ (Kjellberg, 2011). Unions are embedded in 'the Swedish model', characterised by three main processes: an extensive social democratic welfare state, the organisation of institutionalised, centralised and collective negotiations between employers and unions, and the ambition to emphasise consensus rather than conflicts (Thullberg \& Östberg, 1994). The power resources of the Swedish labour 
movement, and high levels of union density - rising continuously from the 1920s and onwards and peaking at about $85 \%$ in the mid 1980 s - are commonly seen as the most important conditions for the development of the Swedish model (Korpi, 1983). Between 1890 and the early 1930s, the instability of the Swedish labour market undermined the political legitimacy of the government, trade unions and employers alike. This was resolved through a 'historical compromise' between unions and employers established in the 'Saltsjöbaden agreement' 1938. It requires the state to abstain from interventions into labour market negotiations, employers agree to collective bargaining, and unions agree to strike only under specific circumscribed conditions. It also specifies which kind or working conditions are open for negotiations and which are not.

Through increased centralisation, the internal democratic structure of the union weakened over time. Some scholars criticise the Swedish model as neo-corporatist, or state corporatist, maintaining order on an employer-dominated labour market (Lewin, 1994). During the 1990s and 00s neoliberal privatisation has weakened the decommodifying institutions, in particular the health and unemployment insurance programmes (Lundström, 2011), and in 2007 the liberal-conservative government raised fees for unemployment funds, traditionally managed by the unions, thus undermining their strength. The increasing mobilisation of employers (Ryner, 1999) against organised labour has exacerbated that effect.

\section{Disconnected spaces: environmental unionism at headquarters and at the shopfloor}

The analysis is based on life-history interviews with Sven Nyberg and Lars

Henriksson. Sven worked at LO headquarters in Stockholm between 1987 and 2008 as an environmental policy ombudsman. He grew up with blue-collar parents and mentions his father, a factory worker and an active trade unionist, as a strong influence on his life. Sven describes himself as leaning towards the left within the social democratic party, of which he has been a member since the late $60 \mathrm{~s}$, and simultaneously as feeling a profound personal identification with the tradition of social democracy. After acquiring a university degree in political economy, political science, and ethnography, Sven worked first as an $S S U^{4}$ representative and then, between

\footnotetext{
${ }^{4}$ The Swedish Social Democratic Youth League (Sveriges Socialdemokratiska Ungdomsförbund, SSU) is a branch of SAP and LO.
} 
1974 and 1987, as a researcher at the municipal workers' union (Kommunal). In 1987 , he was recruited to work for the 'environmental unit' at LO, to develop the official LO environmental program. He continued to work at headquarters with environmental issues until his retirement in 2008.

Lars has been working at Volvo' s car plant in Torslanda, Gothenburg, where he has also been active as an IF Metal/F unionist, since 1978. Lars describes his parents as 'deeply non-political' white-collar workers, and he says his own radical socialist awareness started in his younger teens, initially in relation to the Vietnam War. Soon after this, he became engaged in school politics and affiliated with the socialist movement, identifying himself as a Trotskyist. Lars finished high school with A-level grades and went on to the university to study mathematics and physics, but because he felt so uncomfortable with the university environment, he applied for a job at the local car plant, thinking he would go back to university after a year. However, Lars has remained at the factory, where he has been engaged as a union representative, and also founding and editing a local union newsletter. From the very beginning of his union activism Lars belonged to an oppositional socialist group in IF Metall. Through participation in the anti-nuclear movement he developed an environmental perspective and a critical stance towards the climate impact of the auto industry. While Sven has made a class journey from a blue-collar background to a white-collar intellectual, Lars has travelled 'downwards' in conventional terms, from a whitecollar background to a blue-collar occupation. However, it needs to be stressed that Lars does not content himself with working at the assembly line. He is a freelance writer and a public intellectual, appearing in the media.

\section{Crisis: backlash or opportunity?}

While both Sven and Lars have been actively engaged with environmental issues in the same organisation during the same period, it appears that their work was neither connected to other environmental activities in LO, nor frames their respective environmental work in LO. Both also express disappointment regarding the outcome of their environmental work. In Sven's case, this is most clearly illustrated by his story of working with LO's environmental programme between 1987 and 1991. When

\footnotetext{
${ }^{5}$ Industrifacket Metall (IF METALL) is the second largest affiliate of LO. It was organized in 2006 through a merger of the Swedish Industrial Union (Industrifacket), and the Swedish Metalworkers Union (Metall). Currently, it represents around 325.000 members (http://sv.wikipedia.org/wiki/Industrifacket_Metall).
} 
environmental awareness in society increased during the 1970s and 80 s, the unions took it up mainly as a health and safety issue while problems external to the workplace were rarely considered. As knowledge about the relationship between production and environmental degradation increased and government legislation developed, discussions intensified. Within the metal and chemical unions, the impact of production on workplace safety as well as the environment was becoming particularly evident, and they called to LO for guidelines. To handle new environment regulations a specific environmental unit was established at LO headquarters after the 1986 national Congress, at which it was decided that an environmental programme for LO was to be developed (Nyberg, 2012). The programme (LO, 1991) was presented and accepted at the 1991 National Congress. It included proposals for a number of different environmental actions and reforms, and suggested a right for union reps to stop jobs that were harmful to the external environment. The programme, which was considered to be progressive at the time, was based on four principles:

1. Environmental legislation does not cause unemployment - instead, over time it creates jobs.

2. Internal and external environmental issues need to be integrated.

3. Environmental policies and redistribution policies need to be integrated, i.e.; environmental reforms need to be designed so that they can be exercised by everyone.

4. There is a need to promote environmental awareness at workplaces and among members through education (Nyberg, 2012, translated by the authors).

The programme shows that unions can develop quite thorough environmental policies when support in society at large is strong. However, as the financial crisis of 1992 took hold, interest in environmental work diminished significantly within LO. When Sven talks about the failure of the programme to make a more lasting imprint on the organisation, he talks about the crisis as the most important factor:

Sven: It was poor timing, [the programme] came at the same time as the 90's crisis, and then it all died. All this rather enthusiastic work died almost completely [...] There was [...] no inspiration left [...] all of a sudden there was mass unemployment.

Even though there was support for environmental perspectives in LO at this time after all, the national congress commissioned the programme, an environmental unit 
was established at headquarters, and a majority of the congress accepted the programme - this waned significantly when the economy was threatened. This reflects the influence of the 'jobs vs. environment' conflict on processes of integrating environmental perspectives into the union agenda (Räthzel \& Uzzell, 2011). Union policies are embedded in a mode of production marked by what Marx called the 'metabolic rift'. The concept is one of the pillars upon which Foster develops 'Marx's Ecology' (Foster, 2000, p. 155f). It argues that the capitalist industrial system exploits the earth without restoring its constituents to it. More generally, Marx defined the labour process as metabolism (Stoffwechsel) between nature (external to humans) and human nature. When humans work on and with nature to produce the means of their survival, they also develop their knowledge and their capabilities, and transform their own human nature (Marx, 1998). Polanyi later reduced the concept of the 'metabolic rift' to the commodification of land (Polanyi, 1944), thus paving the way for a perspective that sees the solution in the control of the market, but disregards the relations of production as they are lived by workers in the production process. But to understand why trade unions have difficulties developing and especially holding on to environmental policies it is important to recognise that since nature has become a privately owned 'means of production' it has become workers' Other. Unions have been reduced and have reduced themselves to care only for one part of the inseparable relationship between nature and labour. On the everyday level of policies this means that environmental strategies lose momentum in times of economic crises and when jobs are seen to be threatened. In this respect unions are no different from political parties and governments. In spite of numerous publications by the ILO and Union organisations, which show that a move to a 'green economy' can create new jobs (Poschen, 2012; Rivera Alejo \& Martín Murillo, 2014), unions have been reluctant to exchange 'a bird in the hand for two in the bush' - even if the bird in the hand becomes elusive.

In the interview with Lars, he presents a different explanation from Sven's as to why environmental work in LO has not had any long-lasting effects. In 2011 Lars published his book Slutkört (Henriksson) ${ }^{6}$ in which he argues that car production needs to be converted into socially useful production, and that unions need to be a driving force in this process since workers have the necessary knowledge and

\footnotetext{
${ }^{6}$ The title translates roughly to 'The end of the road'.
} 
experience to realise such a conversion. Lars perceived the crisis as an opening for radical transformation, since the car industry was threatened with massive job losses. The book aimed to complement Lars' work at the workplace by initiating a public discussion and reach out to the union leadership:

Lars: When things were really going to hell, somewhere around 2008-2009, when it was uncertain whether Volvo would survive [...] people were getting desperate [and] even started talking about nationalising and things like that, that no one had talked about for 30 years. When your back is against the wall, having read some science fiction can be a good thing.

$[\ldots]$

So I wrote [the book] to get a discussion going. Even if I'm happy with the book, it was probably my life's biggest failure. Because I don't think I've ever spend so much energy on something that's given so little in return. There was no discussion. I've been travelling to talk about it [...] I held some lectures [...] I talked in seven cities in six days [...] but no reaction whatsoever from where I was really aiming - the trade union movement. Absolute silence [...] At the Book fair 2011, I was on a panel [with] Stefan Löfvén, my trade union president $^{7}$ [and] at that time Saab was at a standstill [...] And I said to him: 'Isn't this an opportunity for the trade union to make an alliance with the environmental movement, to take advantage of this standstill [...] to produce what the society needs for environmental adaption, and in this way to save jobs?' And the only thing he answered was: 'Well, it's sad that you don't believe in Saab'

[...]

With the presidents of Friends of the Earth, Climate Action, I wrote a letter to the president of $L O[\ldots]$ that he should prioritise the climate issues [...] let's meet and talk about it. [And] some employee at the LO-castle [...] had a small meeting with [us] and discussed this. At least he didn't slam the door in our faces. After that there's been nothing.

Comparing Lars' and Sven's perception of the crisis one could simply state that Sven was right to see it as a moment when 'no inspiration was left' and Lars was wrong to believe it would open up the possibility of change. Lars locates the conditions for mobilising engagement precisely in the moment of the crisis. As things are 'going to hell', a 'desperate' situation is created in which discussions about more radical transformation processes can be initiated and indeed, did surface. A distinction can thus be made between revitalisation processes that are organised in accordance with a logic of accommodation, seeking solutions 'within existing economic and social relations' (Serrano, 2014 , p. 4), or with that of transformation, in which case they challenge the established union perspective. While accommodation depends on the

\footnotetext{
${ }^{7}$ Löfvén, who used to be the chairman of IF Metall, is currently the leader of SAP, and as of September 2014, the current prime minister of Sweden.
} 
consent of leadership, and a fairly stable economy, transformative initiatives are more likely to gain momentum as mobilisation 'from below' in times when current modes of production become incapable of providing employment even in the short term. But the question is, why did Lars and Sven evaluated the respective crises they confronted differently? Lars sees himself as speaking from the point of view of workers, who were to lose their jobs but had the capacity to turn their fate around by inducing radical change. Sven speaks as somebody who analyses the processes at headquarters from an insider position, but without the power to change them. However, for both protagonists, the headquarters are decisive. In spite of Lars' successful work at factory level he is convinced that radical transformation can only happen if the 'LO-castle' becomes active. The conditions for dialogue are constructed as depending either on the attitudes of the other, or on external circumstances. This suggests that LO is seen as an organisation where policy changes need support 'from above'. Moreover, Löfvén's reaction to Lars' suggestion indicates that the LO leader puts more faith into the SAAB management than the capacity of workers to create change. That Sven and Lars both experience a sense of failure shows that the problem cannot be framed as an issue of passive leadership versus spontaneous rank and file (Zeitlin 1987; Hyman 1989), since Sven has been a union official at LO headquarters. The next section will examine how both unionists experience the limitations of initiating an environmental debate within LO.

\section{Union culture and institutionalisation}

Sven and Lars identify the traditions and cultures of Swedish trade unions as obstacles to integrating concerns for work and nature.

Sven: A reflection that I gradually made was that the culture that we have in Sweden obviously [is] pretty cemented. Health and safety is a trade-union thing, [but] the environmental work is something rather academic, it comes from the universities, the environmental organisations and things like that. It's sort of different worlds. When I meet people from Brazil, Mexico, Africa, [and] Southern Europe, they're closer. That's obviously because they're not part of the establishment, and [...] more underground. It's easier for them to work together without [loosing] prestige [...] But it's rubbed off, the European trade union has had much cooperation with [...] the joint committee of the environmental organisations, and also with the social NGOs [...] so it's been kind of a three party collaboration between the environment, the trade union and social NGOs in Europe. 
When Sven describes unions in other parts of the world as being 'close' one might first interpret this as being closer to the effects of environmental degradation, especially climate change. But from the context it transpires that he means being closer to environmental groups, with whom they can work together without 'losing prestige'. In Sven's view, being closer to environmental movements is dependent on being further away from the establishment, from government, companies and political parties. Indeed, as our research in the global South has shown, labour and environmental movements work closer together in some of those countries. A member of the FOBMS (Brazilian Forum of NGOs and Social Movements for the Environment and Development) answered our question about the cooperation between environmental and labour movements by saying: 'The Brazilians, yes. Because from our history, tradition, it is natural to integrate. So we always say socioenvironmental. It's more common to use socio-environmental than just environmental. Because of all this tradition of the movements in the Amazon and - I think that it's impossible to split'. The tradition she refers to is exemplified by Chico Mendes, simultaneously a founder of the trade union of rubber tappers and an environmental movement to protect the Amazon (Mendes, 1992). The issue that Sven raises, points to the ambiguous position of civil society organisations in relation to the 'establishment', to the dominant power structures. In countries like Brazil, South Africa, but also Spain, the unions' history of resistance against the state is still alive and they see themselves as a movement among other movements than as part of a system of governance. However, crises in the countries we investigated have created divides within the unions regarding their roles as movements against the state, in South Africa and Brazil to a state they helped to bring into power. When unions become integrated into dominant institutions they not only have difficulties organising collaborations with movements that are more critical towards such institutions, they are also less able to provide a space for union transformation. In this sense, when Sven describes the unions of the South as being 'closer' the fact that they are closer to other movements reflects their more recent history as a social movement themselves. Sven suggests though, that the more established unions can learn from the less established ones from the global South when it comes to environmental policies. This touches the question whether there is a possibility for 'union renewal', which we do not have the space to discuss here (Fairbrother and Yates, 2003). 
According to Lars, the lack of an environmental awareness in unions needs to be understood as a consequence of misrepresentation:

Lars: It's no coincidence that, [in] the Swedish union movement, [environmental] issues don't even exist. This is because it has been so tightly connected to one party and one strategy for such a long time. The Social Democrats have made the decisions for the trade union, and the strategy has been to focus on the export industry - to let them make profits, and to ignore everything else. That's the whole idea of the loyal wage policy.

Lars argues that corporatist configurations of labour relationships have thwarted the conditions for articulating an environmental agenda from the standpoint of workers. Environmental initiatives from 'below', Lars explains, need to challenge and transform the hegemonic discourse within the union to become successful. The two last quotes illustrate that developing environmental union initiatives in the Swedish context requires breaking up 'cemented' union traditions. In spite of their different positions, both protagonists agree that the union needs to sever its links with the institutions of power in order to embark on a meaningful environmental agenda. But both also differ as a result of their different political positions:

Sven: Why didn't we manage to better pick this up in [...] investment policy proposals? There were such suggestions from LO later [...] but [while] the leadership was sympathetic [to the environmental program], they didn't really take it to heart. [...] There wasn't anyone in the leadership who said: Now, this is what we're doing - this is LO's big environmental investment!

Sven links his vision primarily to activities at the top of the confederation, in the form of financial policy proposals and attempts to influence opinion through public statements by union leaders. This locates the conditions for change in the capabilities of the leadership and suggests that when unions are recognised as influential political actors they develop a culture where organising member support becomes secondary. Unlike Lars, who frames the limited support of the leadership as a conflict of interests, Sven - who is closer to the leadership in the organisation conceptualises the lack of leadership consent in terms of a lack of personal passion for the issue. The experiences of Lars and Sven suggest that the highly developed institutionalisation of LO, in accordance with a corporatist logic, undermine union transformation processes. 
Mobilisation and transformation - the relationships between 'top' and 'bottom' A core theme in Lars' work with climate issues is the notion of converting production in order to meet social needs and sustainability demands. While he feels that pushing this notion within LO is difficult today, it is for him the only way for unions to simultaneously protect jobs and combat climate change:

Lars: The key issue are jobs and adaption, I think. [...] I see no practical possibility to do that today, but that's largely why I wrote this book, to get a discussion going [...] the idea that we could drive this from the bottom, and adapt this company, is total science fiction to most people. We're so micromanaged and controlled, can't even decide which hand to hold the machine with [...] That's why we took this sort of, almost like a media strategy, towards the LO leadership, to get a discussion with them. And, best case scenario, we could get some sort of approval from above.

Lars describes 'the idea that we could drive this (the conversion of production) from the bottom, and adapt this company as something most people saw as 'science fiction'. His vision of transformation is that of a movement from below, and his union work has been characterised predominantly by strategies to support members' empowerment in his plant. But the control system of the company has been so powerful that workers did not believe in their own capabilities. Therefore, Lars sought the solution in a public discussion and in 'leadership approval'. What this shows, is not only an insight into the power of the leadership and thus into the specific LO culture, but also the degree to which a radical environmental position is marginalised in the union and among workers. Lars and people like him in the union are thus caught between a rock and a hard place: The inertia of the established union structure and the workers' lack of confidence in their transformative powers. One can of course argue that the latter is not only a result of company control, but also an effect of the absence of union mobilisation.

When Sven talks about whether or not the implementation of environmental issues has been a top-down process in LO, he says that while the engagement came from below at the beginning, the push from headquarters was necessary:

Sven: One thing that l've [...] thought a lot about [...] is: To what extent has this environmental policy work at LO been a top-down process and how much is bottom-up, so to speak? And [...] In general I [...] think that, it's not a purely top-down process. Because after all, [it] came from below, once. It was union clubs, mainly on the industry side, who said [...] we need help dealing with 
[environmental issues] and then [the] congress decision came [...] But I think it's wrong to say that there's been a permanent pressure from the bottom, that LO should do this and that. It has sometimes heated up and [...] when it heats up, that's when people get involved [...] But I can't separate that from the feeling that [...] if we hadn't pushed it centrally, then nothing would have happened.

While both Sven and Lars identify mobilisation from below as crucial, Sven also draws attention to the need for intervention from above. However, neither he nor Lars recount any significant moments at which the interests and demands of members are brought into the process, except right at the beginning of the environmental debate. Relating this to Gramsci's concept of organic intellectual, one could say that the way in which the leadership has pushed the issue as Sven describes, has not been articulated with the interests of the members in a way that a new environmental consensus could emerge. To develop a consensus, that is a 'collective consciousness' among workers, is Lars' predominant goal:

Lars: For me the most important lesson, [from working] in the trade union the important thing is to unite people from the bottom up. To not try to find the most politically well-reasoned [issue], but [...] work with the questions that exist [...] amongst the majority. And to not do more than the majority is prepared to. [...] That you don't [...] make yourself into some avant-garde and request people to follow you [...] the whole point is to create a collective. One of the big problems, I think, [is that] there is no collective consciousness. [...] [So] today, [...] my project [is to] in every conceivable way create collectives, a feeling of being strong together. And that can be about the smallest things, it doesn't have to be the big political issues. It's rarely about the big political issues, unfortunately.

While Lars acts as an organic intellectual in the public realm and with the trade union leadership, he consciously restricts his activities at the workplace to support his fellow workers in what they already want, rejecting the role of 'avant-garde'.

Unintentionally, his division of work reproduces and reflects the split between labour issues (belonging in the factory) and environmental issues (belonging to a different space), the world of academia and the middle classes. It is important to understand his reluctance of becoming 'avant-garde' as a lesson learned from the devastating role that some forms of avant-gardism have played in the workers' movement historically. And perhaps his experience of the failure of his book to bring about debate and change has reinforced his desire to concentrate on the workplace. However, it might be that there are forms of being avant-garde which are not 
opposed to building up collectives from the bottom up. Taking into account the aversion of parts of the workforce against 'academics' and the middle classes it might well be that Lars, coming from a middle class background, sees that he may lose the trust of his fellow workers if he attempts to go 'too far' in introducing new ideas. However, Lars himself regrets that his fellow workers are not open to discussing 'big political issues'.

\section{'Enthusiasts and polished people'}

When Sven talks about his experiences from working at LO headquarters, his relationship to members is not discussed as having been very central. Instead, he highlights other relations, such as contacts with authorities, government bodies and other union organisations. Below, Sven talks about the difference between working at LO headquarters and his previous work at the LO member organisation Kommunal:

Sven: During my Kommunal years there was questioning [...] communication could be pretty straight-forward: [...] 'What you're doing is crap' [...] 'We don't accept that explanation' [...] It was give and take, it was rather fun. At LO I've sort of been communicating on the level above. A lot of regular members at courses and things like that as well, but it's often been union officials [and] more established people, who are also slightly more polished $[\ldots]$ My old union Kommunal had a project that I was involved in, where I got to know [...] local people [...] from outside [...] enthusiasts. They were really passionate about their questions, and [...] struggled [...] because no one really cared.

What shines through in this account is that being straightforward and critical is connected to being enthusiastic and passionate about a project; being established and polished is implicitly related to being less passionate. Though the passionate people are the local people outside of the union, Kommunal does work with them, which indicates that they are at least not averse to passion. Thus, work at headquarters is marked by a lack of connections to people who feel a personal engagement with environmental issues. The quote below shows how Sven describes the relationship between his work and the engagement of members in more detail:

Sven: If I'm at a conference and get a couple of hours [to talk about] these issues [...] they think it's super interesting while we're talking about. [...] Then they get back to their own reality. [There's a] lack of [...] continuity in the structure of the organisation [...] The interest is always there, [but] it needs to be watered to grow. The labour movement isn't a reading movement; it's a 
discussing movement. Writing all these programs, it's a good thing and a prerequisite, but it's far from enough. I'd like to be able to split myself, be out talking to people [...] Then [...] things can start happening

[...]

you're dependent on enthusiasts [...] because when [they] disappear [...] it all dies [...] until there's someone new [...] I've been to quite a few [places] and talked, if $[. .$.$] there's an enthusiast there who wants me to come.$

Sven's account not only illuminates the importance of individuals for organisational transformation but also the need for different kinds of individuals in different positions: grassroots enthusiasts are needed as much as people who can write documents and communicate their knowledge to initiate discussions in a context where reading is not the dominant practice. But the cooperation between different kinds of competences and activities fails when there is no regular, built-in cooperation between headquarters and members. For Sven building up bottom-up mobilisation is dependent on finding the local enthusiasts. But even they cannot hold up the momentum where cooperation is not built into the day-to-day work of people at headquarters and people at the local level. Under the existing conditions both Lars and Sven have to divide their engagement between communicating at the bottom and at the top. Both have capabilities to communicate in both areas but the impermeable structures of the organisation have so far made it impossible to combine these capabilities in a productive way. There seems to be no structure that allows a meaningful communication between enthusiasts on the local and on the higher levels of the organisations. It is not so much the hierarchical structure as such that prevents change but the absence of structures that enable cooperation on a regular basis. There are enthusiasts and organic intellectuals in the leadership and among the rank and file, but, as in the case of Sven and Lars, they do not meet. Thus, the ability for both to act successfully as organic intellectuals is limited.

\section{The Spanish example: some conditions for success}

The examples of Sven Nyberg and Lars Henriksson have taught us something about the specific difficulties of the Swedish Confederation LO to take climate change as seriously as jobs and working conditions. We have tried to explain how the way in which Swedish unions have become part of the system of governance is linked to the divide between headquarters and rank and file members, which in turn limits the space of action for organic intellectuals from above and from below to initiate change. In what follows we introduce an example from Spain, to show that in different historical conjunctures unions can become environmental innovators. Spatial 
limitations prevent us from doing justice to the Spanish case. Nevertheless, we believe that a contrasting example can help us to better understand the specificities of the Swedish case.

The first union, internationally, to create a post for an environmental secretary was the Spanish Comisiones Obreras (CCOO) in 1991. In 1994 a research centre for health and safety and the environment was founded (ISTAS), whose basic resources were financed by the union. It was an elected representative, Joaquín Nieto the leader of a left political faction, who led the union's climate change/environmental initiative. The Secretary General wanted to integrate all factions and one of his strategies was to form a unitary and pluralist executive board and thus he offered Joaquín a position on the board. Through his political engagement in socialist policies, his study of Marxist theory and his passion for work, he had come to the conclusion that climate change and nature were neglected but crucial issues for trade unions. Through his discussions with the ecological movement he identified three main areas that needed to be tackled: climate change and energy, biodiversity and water, and chemical pollution:

Joaquín: In these three areas we had to set up union activities, and we had to investigate what kind of conflicts had already developed in the work places, how they could be solved, how each problem could be followed up to develop suggestions, to follow and develop the international agenda in Europe and in the world.

What is strikingly different from the Swedish case is the almost taken-for-granted link Joaquín draws between the workplace and an international agenda. While programmes were written and the public domain was used to initiate debates, Joaquín also created a structure to connect environmental issues with workers' concerns at the workplace. ISTAS was founded as Joaquín argued that in other union areas workers had specialists to whom they could turn for support when needed. The Institute grew to a body of 30 technical specialists (e.g., engineers, doctors, economists) coordinating a network spread across all Spanish provinces comprising about hundred technical specialists. It acted as a transmission belt between workers' interests at the local level and union strategies at regional and national level. 
Joaquín was not an employed technician but the leader of a powerful political faction too strong to be overlooked. The CCOO had been a clandestine union fighting against the Franco régime and Joaquín had organised workers against the Franco dictatorship. He had support from below and was able to use it. Having been a factory worker he found it necessary to connect environmental issues with workers' grievances. This was not without conflicts: 'Miners love me and hate me', he said. They loved him because he helped to make their workplaces safer and hated him because he told them that their production had to go in the long run. Joaquín did not shy away from suggesting changes that went beyond workers' immediate interests, and acting as 'avant-garde'. Joaquín's engagement in the revolutionary history of the CCOO shaped his capabilities to act and this history in turn created the affordances for union transformation, which he realised together with many others. When he became environmental secretary, the post-Franco democracy had only existed for 16 years and the union's urge to change not only working conditions but also society at large remained vibrant. Against this background Joaquín can be understood as embodying both Lars' aim to create a collective consciousness from below and Sven's desire to connect enthusiasts from below and from above.

However, with the current economic crisis the environmental engagement of the CCOO is suffering a backlash: with a sharp decline in the union's resources, those who want to build a more apolitical, corporatist union are gaining power and their first target is the environmental policy. Funds have been withdrawn, and technical staff has left the union because they see no future for an environmental union project. Like Lars, Joaquín and others hoped the crisis would make it easier to suggest a different kind of development, centred on quality as opposed to quantity. But though environmental issues still have a strong presence on the CCOO homepage (in contrast to the LO homepage) they have not won their argument - yet?

\section{Concluding remarks}

Our case studies show the interrelationship between organisational and individual trajectories as well as socio-political conditions in the making of organic intellectuals. In Sweden, the history of the unions as a movement aiming to change not only working conditions but also societal conditions at large plays no decisive role in the everyday politics of the union. Instead the union is a civil society organisation that 
has become part of the system of governance. For activists like Sven and Lars who try 'from above' and 'from below', respectively, to bring about transformative change this entanglement with political and economic power acts as a barrier. The individual trajectories of Lars and Sven have motivated them to become environmental activists in the union and have positioned them differently within the union hierarchy. While Lars feels most comfortable as part of the workforce on the ground, Sven followed the call into the union hierarchy. By rejecting an 'avant-garde' role, Lars sets parameters on the degree to which he can be transformative at the workplace, while Sven wanders only occasionally into the places where he finds the local enthusiasts. However, ultimately it is the lack of a structure organising regular communication between 'above' and 'below' that limits the possibilities of both unionists to be successful as organic intellectuals. Thus, they have been unable to create new workers' identities which overcome the divide between nature and work.

The Spanish case reveals a unionist who is able to combine on the ground experience with the willingness and ability to become a transformative leader in his union. What helped him overcome the split between 'above' and 'below' was the specific context of the $\mathrm{CCOO}$, a union, which was born in the struggles against the Franco dictatorship and therefore never saw itself as working purely to improve working conditions, nor did it delegate its goals of political change to any political party. For Joaquín being a leader includes articulating perspectives that go beyond the already existing demands of workers. In this sense he is not just a leader but an organic intellectual aiming to create a new hegemony that would enhance the union's capacity to act. This does not stand in opposition to but is a form of creating new collective identities. Due to the character of the CCOO in Spanish history, Joaquín has been able to initiate transformative change. But even here, the economic crisis puts pressures on the union to reduce itself to workplace representation. Not only the economic crisis, but also the process of institutionalisation visible in the unions' estrangement from new social movements in Spain, puts the union's environmental engagement at risk.

One of the guiding issues of our research is the role of crisis for transformation. Our three protagonists interpret the role of crisis differently. Lars and Joaquín see it as an opportunity to discuss new forms of societal development beyond the notion of 
material growth. At the beginning we referred to the crisis which unions are seen to be experiencing today. Walter Benjamin conceptualised such a crisis as 'moments of danger' (1969). During such times, organisations, in our case unions, may opt for adaptive strategies, accommodating themselves to the dominant order of the current production system, and focusing on those policy areas and strategies through which they have grown historically. Given the successful history of trade unionism in Sweden, such strategies are easier to legitimise. Benjamin warned that conformism may 'overpower' tradition. Such conformism, an adaptation to the given economic system by trying to save as much as possible of what has been achieved may undermine the possibilities to master the crisis precisely because it blocks the transformations, which are needed to confront new challenges. Benjamin argued that in order not to become reduced to a 'tool of the ruling classes' organisations and individuals need to break free from conformism. It is not conformism but transformation through which tradition, in our case the tradition of protecting workers rights and lives, can be rescued.

\section{References}

Bass, B.M. (1999). Two Decades of Research and Development in Transformational Leadership. Eur. J. Work Organ. Psychol. 8, 9-32.

Benjamin, W. (1969). Theses on the Philosophy of History. In: Hannah Arendt (ed.) Illuminations: Essays and Reflections. New York: Schocken

Caldwell, R. (2003). Models of Change Agency: a Fourfold Classification. Br. J. Manag. 14, 131-142.

Castells, M. (2000). The rise of the network society, 2nd ed. ed, Information age. Blackwell Publishers, Oxford: Malden, Mass.

Fairbrother, P., Yates, C.A.B. (Eds.), (2003). Trade unions in renewal: a comparative study, Employment and work relations in context series. Continuum, London; New York.

Flyvbjerg, B. (2006). Five Misunderstandings About Case-Study Research. Qual. Inq. 12, 219-245.

Foster, J.B. (2000). Marx's ecology: materialism and nature. Monthly Review Press, New York.

Frege, C. M., \& Kelly, J. E. (2004). Varieties of Unionism: Struggles for Union Revitalization in a Globalizing Economy. Oxford: Oxford University Press.

Geertz, C. (1973). The interpretation of cultures: selected essays. Basic Books, New York.

Gibson, J.J. (1979). The ecological approach to visual perception. Houghton Mifflin, Boston.

Gramsci, A. (1999). Selections from the Prison Notebooks, Essential Classics in Politics: Antonio Gramsci. The Electric Company Ltd, London. 
Gray, A. (2004). Unsocial Europe: social protection or flexploitation? London: Pluto Press.

Hampton, P. (2015). Workers and Trade Unions for Climate Solidarity: Tackling climate change in a neoliberal world. London: Routledge.

Henriksson, L. (2011). Slutkört. Stockholm: Ordfront.

Holstein, J., \& Gubrium, J. F. (2003). Inside interviewing: New lenses, new concerns. London: Sage.

Holzkamp, K. (2013). Psychology from the standpoint of the subject: selected writings of Klaus Holzkamp, Critical theory and practice in psychology and the human sciences. Palgrave Macmillan, Basingstoke.

Hyman, R. (1989). The Sound of One Hand Clapping: A Comment on the "Rank and Filism" Debate. International Review of Social History, 34, 309-326.

Hyman, R. (2001). Understanding European trade unionism: between market, class and society. SAGE, London; Thousand Oaks, Calif.

Kjellberg, A. (2011). The decline in Swedish union density since 2007. Nordic journal of working life studies, 1(1), pp. 67-93.

Korpi, W. (1983). The democratic class struggle. London: Routledge.

Lewin, L. (1994). The rise and decline of corporatism: The case of Sweden. European Journal of Political Research, 26(1), 59-79.

LO. (1991). LO:s Miljöprogram. Borås: LO.

Lundström, R. (2011). Den kalkylerande medborgaren: Bidragsfusk i svensk välfärdsdebatt 1990-2011. Umeå: Umeå universitet.

Marx, K. (1998). Capital. A Critique of Political Economy, 1887th ed. ElecBook, London.

Mayer, B. (2009). Cross-Movement Coalition Formation: Bridging the LaborEnvironment Divide*. Sociol. Inq. 79, 219-239.

Mendes, C. (1992). Fight for the forest: Chico Mendes in his own words, 2nd ed., Updated and enl. ed. Latin America Bureau; Distribution in USA by Monthly Review Press, London: New York, NY.

Munck, R. (2002). Globalization and Labour: The New 'Great Transformation'. London: Zed Books.

Nyberg, S. (2012). Lo, jobben \& miljön. Arbetarhistoria, 36(143-144), 24-28.

Obach, B.K. (2004). Labor and the environmental movement: the quest for common ground, Urban and industrial environments. MIT Press, Cambridge, Mass.

Polanyi, K. (1944). The great transformation: the political and economic origins of our time, 2nd Beacon Paperback ed. ed. Beacon Press, Boston, MA.

Poschen, P. (2012). Working towards sustainable development opportunities for decent work and social inclusion in a green economy. International Labour Office, Geneva.

Rivera Alejo, J., Martín Murillo, L. (2014). Unions4Climate. Reducing emissions from the workplace and creating jobs.

Ryner, M. (1999). Neoliberal Globalization and the Crisis of Swedish Social Democracy. Economic and Industrial Democracy, 20(1), 39-79. 
Räthzel, N., \& Uzzell, D. (2011). Trade unions and climate change: The jobs versus environment dilemma. Global Environmental Change, 21(4), 1215-1223.

Räthzel, N., \& Uzzell, D. (2013). Trade Unions in the Green Economy: Working for the Environment. London: Routledge.

Serrano, M. R. (2014). Between accommodation and transformation: The two logics of union renewal. European Journal of Industrial Relations, 20(3), 219-235.

Snell, D., \& Fairbrother, P. (2010). Unions as environmental actors. Transfer: European Review of Labour and Research, 16(3), 411-424.

Thullberg, P., \& Östberg, K. (1994). Den svenska modellen. Lund: Studentlitteratur.

Zeitlin, J. (1987) From Labour History to the History of Industrial Relations. The Economic History Review, 4O(2), 159-184. 